\title{
The Issue of Shunting of the Affected Phase in Compensated Medium Voltage Networks
}

\author{
Ivan Cimbolinec ${ }^{1)}$, Jan Švec ${ }^{2)}$ and Jaroslav Hubený ${ }^{3)}$ \\ 1) 2) Czech Technical University in Prague, Faculty of Electrical Engineering, Department of Power Engineering, \\ e-mail: ${ }^{1)}$ ivan.cimbolinec@seznam.cz, ${ }^{2)}$ jan.svec@cezdistribuce.cz. \\ 3) ČEZ Distribuce, e-mail: jaroslav.hubeny@cezdistribuce.cz.
}

\begin{abstract}
Permanently increasing size of the capacitive currents in medium voltage networks becomes a limiting factor in their operation. This negative trend is manifested especially in the mixed networks, where the proportion of cable gradually increases in comparison with the overhead medium voltage lines. The residual currents in the one-pole insulation faults in the medium voltage system, in insulation fault site are continually increasing. Large investment funds are necessary for full elimination of the fault currents, while other known ways used in the partial elimination of the size of the fault currents have some technical limitations. In this article, the positive and negative sides of the method "Shunting of the affected phase in compensated medium voltage networks" are then evaluated.
\end{abstract}

Keywords - shunting-method, rehabilitation of the affected phase, CI paradox.

\section{INTRODUCTION}

Theoretical advantage of compensated medium voltage networks is the possibility of their operation even with onepole insulating failures without having any impact on customers in categories B, C, D. It would be much better to stick with the famous proverb "Grey is a theory, but green is a tree of life". Practice in operating these net-works shows the real status of the whole issue, which brings different experiences with many negatives. There is a number of conditions that must be met in order for the medium voltage network to continue to operate with a single-pole insulation fault. The assumption that a compensating choke of several MVA nominal power to compensate for the capacitive currents of the entire system with a total capacitive currents from $300 \mathrm{~A}$ to $450 \mathrm{~A}$ can be an optimal solution, the assumption is usually unrealistic. Although the technical standard ČSN 333070 and other related standards admit that the compensation is necessary up to approx. $15 \mathrm{~A}$ of the total capacitive current of the system, practice shows that even relatively small residual fault currents below 10 A cause in short-time overhead line and cable fault files or emergency damage compact high voltage switchboards. A very unpleasant consequence of these phenomena at the break of the medium voltage conductor is the voltage unbalance at the low voltage level. Under these conditions, when there is a loss of rotating electromagnetic field, three-phase induction motors cannot be operated and, for the same reason, thermal damage to the coils of the HDO-operated contactors, start-up fridge relays, and the performance of electric heat appliances.

The operation of compensated IT networks with a singlepole isolation failure is therefore a certain compromise, with the distributor trying to find fault in the shortest possible time until the phase conductor breaks, to cause a phase to phase short circuit. In case of phase to phase short circuits on overhead or cable lines, operation under these conditions is no longer possible, with voltage and phase asymmetry caused by the broken conductor being very limited.

\section{COMPENSATED NETWORK OPERATION}

When operating compensated medium voltage networks, we make many mistakes and we often overestimate the possibilities of this system, even if we have not any backto-back information on the behavior of the system with the existence of one-pole isolation faults in the system and we are working with an open feedback loop. Let's look at the basic misconduct in their operation.

\section{A. Capacitance System Asymmetry}

The size of the capacitive asymmetry of the high voltage system powered by a particular $110 \mathrm{kV} / \mathrm{MV}$ transformer station has a significant effect on the quality of its own compensation. While the capacitive and therefore the voltage unbalance of the phase conductors against ground potential is very low for cable networks because of the geometric symmetry of the cables, there are cases where the voltage of unbalance $U_{0}$ in the predominantly cable systems is less than $1 \%$ of the rated phase voltage, opposite extreme, where the voltage unbalance in mixed high voltage networks was $18 \%$ of the rated phase voltage. In the first case, the automation of the compensating choke tuning was paralyzed, an amplifier had to use for increasing the $U_{0}$ value. In the latter case, it was not possible to tune the choke to a resonance state, since at the tuning near the peak of the resonant curve the specified voltage unbalance, which is usually set to $30 \%$ of the nominal phase voltage, was exceeded. In addition to a fictitious ground connection, this condition caused such large differences between the phase voltages of the three-phase system that, in this state, large rotating machines, such as customers in surface brown coal mines, were automatically disconnected by the protectors. Aligning the choke was followed in particular by voltage symmetry, and then as a secondary function, the system own compensation of the MV.

Looking closer to some causes of asymmetry, we will soon find them. MV overhead lines often pass through forest intersections, and some cylindrical "isolation space" burns around each other; otherwise the line touches one phase of the edge of an unheated forest aisle. In both cases there is a considerable capacitive asymmetry due to nonmaintenance of the aisles. In less frequent cases, operators connect to the cable outlet in difficult terrain an additional conductor to a certain operating phase, in particular by following the possibility of faster and more convenient 
repairs, especially in winter. The maintenance of the line is also related to the state of the supporting and suspension insulators and the condition of the atmospheric overvoltage limiters on the overhead lines (Torok tubes), which is often despondent, some limiters are completely missing, others are partially burned.

Thus, capacitive asymmetries can be said to be due in particular to inappropriate design of the line run and, in particular, to inadequate maintenance, which is related to the trend to minimize operating costs for routine equipment maintenance.

\section{B. Medium Voltage System Operation and Compensation Quality}

In the previous paragraph, we mentioned the most common causes, which lead to a situation of unreasonably large capacitive and therefore also a voltage unbalance. If we already have an unbalance under control, about $5 \%$ to $6 \% U_{\mathrm{f}}$, we can fully pay attention to the quality of our own compensation. The problem is that a person, a dispatcher, or a transformer station maintenance and servicing worker, designer, and other people, always intervenes in this process. Practice shows that operating staff interventions into the automated compensation system during operation do not produce the expected results. From my practice on the contrary, I can confirm, that the entry of people into this process and their inadequate interventions into the system have always resulted in a worsening of the state and, in some cases, the elimination of the entire compensation system. Manual tuning of compensation choke for "phase voltage symmetry" and not to compensate capacitive currents of the system with capacitive currents above $300 \mathrm{~A}$ causes an increase in ground fault current at the earth connection point. An even added error is the disconnection of the chokes from the transformer star node when no single-pole fault is detected or when the choke is poweradjusted to the grid range and is manually or automatically set to a higher harmonic by mistake.

However, the purpose of this article is not to address the demonstrable errors of the distribution system operators, but to show some weaknesses in compensating the MV networks with standard means, including today the method of additional grounding of the affected phase. We have to remind ourselves that even the system of "Swedish neutral" is not immune to the misconducts, described in the previous paragraphs. Operation of the compensated medium voltage networks is based on certain principles and on certain assumptions, based on which we calculate the size of the contact voltage, step voltage and ground systems of the distribution transformer station. Therefore, our goal must be that the assumptions under consideration are justified and that the weaknesses of the operating system are not dangerous to anyone.

\section{COMPENSATION MEANS}

Many of us will recall one of the first means of compensating capacitive currents in the medium voltage system. This means the Bauch extinguishing transformer, which was used mainly in the MV/MV transformer stations, where the transformers did not have a star node run out, or in cases where the secondary winding of the transformer was connected to a triangle. The primary winding of the Bauch transformer was therefore connected to the main bus of the MV substation. In this context, it should be remembered that the capacities of pre-war MV systems were lower.

Post-war industrial development of the then Czechoslovakia was conditioned by the development of the transmission and distribution system, which ultimately led to the growth of the capacitive currents of the systems of all medium voltage levels used. The distribution systems gradually switched to compensating capacitive currents through the Petersen reactor. In the medium voltage distribution systems in the Czech Republic, compensating chokes from the production of EGE České Budějovice, which is the successor company of Energovod Praha and Energetik, are currently being used. Prior to 1956, the Petersen principle of the choke, connected between the transformer winding node and the ground, was improved by Ing. Richter patent. He worked out smooth tuning on the principle of a split core, shifted vertically by an electric motor through a worm gearbox. It is gratifying that a related auxiliary equipment, in particular an auxiliary tuning device, a pole earth fault indicator, an oil power resistor to increase the active component of the fault current, and a resistance automation, were determined by the electromechanical timers to determine the time sequences associated with the resistance connection time and the time of its blocking. All of these elements were located near the compensation choke in the cabinet with the SAR designation. It must be said that this system was principally left behind, but it is still technologically upgraded and supplemented by new resistance automation, a new modular resistance and a choke tuning automation. Compensation chokes with smooth tuning are manufactured in a much wider power range and with the required operating time from two hours to continuous operation. From the viewpoint of monitoring and recording of parameters of uninterrupted operation of the distribution system of individual operators, as amended by Decree 540/2005 Coll. and with regard to the time-consuming difficulty of the location of the ground connection, it is recommended to install the chokes with longer operating time. More pressure can be expected from the Energy Regulatory Office on the gradual strengthening of the SAIFI, SAIDI and CAIDI continuous electricity transmission and distribution parameters.

The ever-growing range of medium voltage distribution networks, especially cable networks, has caused an unprecedented increase in capacitive currents. If we admit that mixed networks can be according to ČSN 332000-4-41 or rather PNE 330000-1 operated up to 450 A capacitive current, it is evident that even the expected residual $10 \%$ fault current $\left(I_{\mathrm{p}}=0.1 I_{\mathrm{c}}\right)$ is very difficult to snuff out. If an inaccurate tune of the arc-suppression coil, the possible arc at the failure point can no longer be extinguished. What this can do in practice is captured in Fig. 1. In this case, the $22 \mathrm{kV}$ system, due to an non-extinguished arc at ground connection to the switchboard bushing, caused the burn through a switchboard cabinet, the SF6 gas leakage and the subsequent three-pole short circuit with the final thermal destruction of the switchboard. The arc-suppression coil of its principle cannot compensate the active component of the fault current, only the Swedish neutral system can do it, however, with the use of high investment resources. 


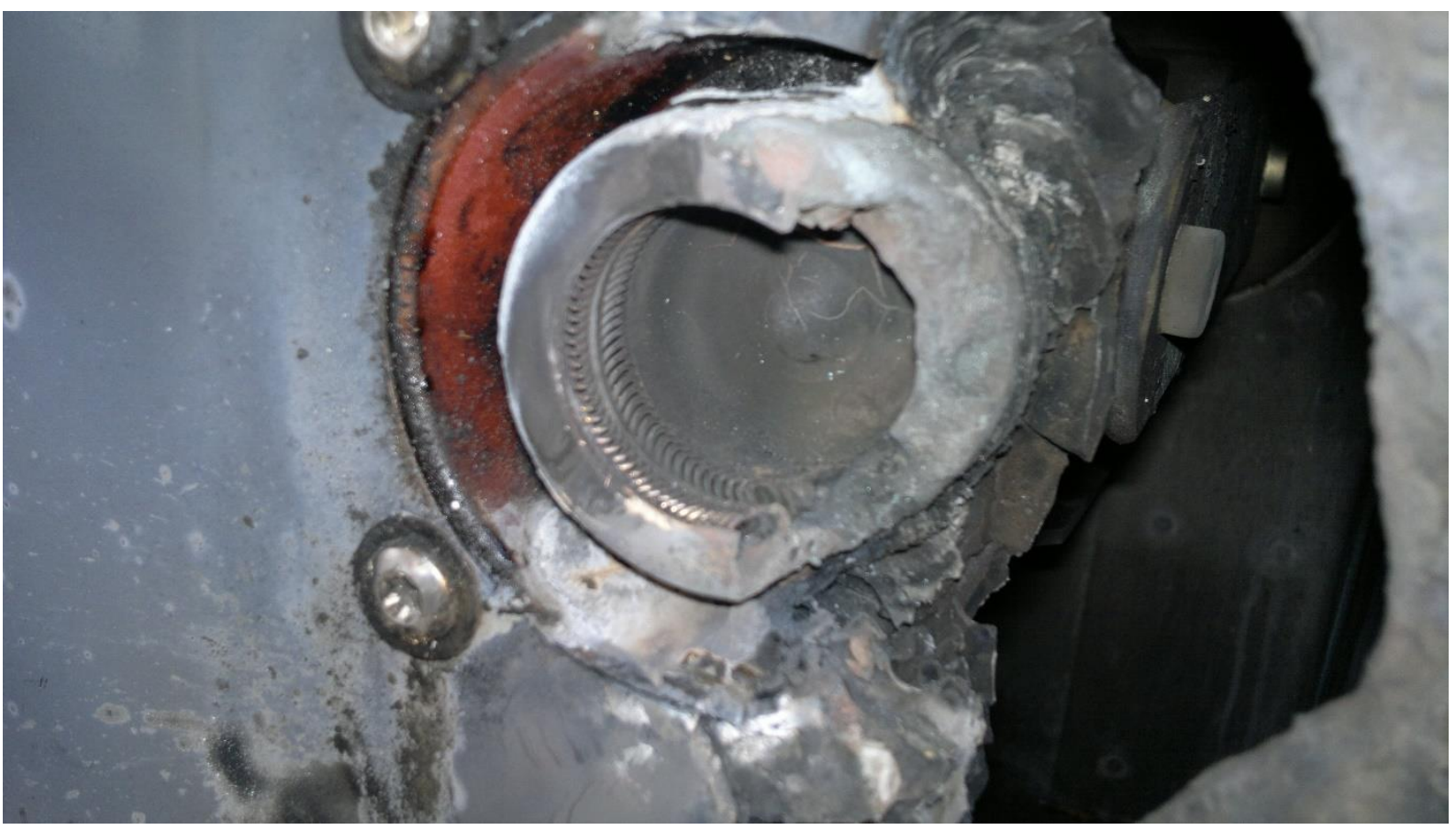

Fig. 1. Consequences of earth connection and $22 \mathrm{kV}$ non-fired arc.

In the recent years other ways have been tried in the distribution systems in the Czech Republic that lead to the reduction of the fault current in the place of earth connection because of the limitation of investment means. One way to limit the size of the fault current is to use a method of the affected phase shunting at a location other than a ground connection.

\section{Method of ReHabiLITAtion of the AfFECTED PHASE}

The principle of the method is theoretically relatively simple. If we are able to divert a part of the fault current from the connection point to the site of the new shunting of this affected phase, it is possible to expect a safe extinction of the arc in the place of the earth connection. The new place of shunting is selected directly in the power substation where we control it. This means that the "bypass to earth connection" we can selectively switch and protect by means of automation and power switches.

It is good to remind the related technical terminology. While in German the familiar word "schunt" is used for the bypass, from the English was taken a complex expression for shunting activity in case of a single-pole isolation fault at additional grounding, thus "shunting". The English term shunting is very often used in medicine, especially in the field of cardiac surgery. In Brno even went a little further, and in accordance with the rules of the Brno "hantec" they began in the year 2013 "šentovat". However, you can expect that the experts and specialists in spite of such language barriers technically agree, and their joint efforts will bring qualitative changes in the then solutions related issues.

\section{A. Principle of the Method}

In the past few years, many authors have gradually taken over foreign professional papers and experience about this method to make them accessible to our professional public. Nowadays, in Czech conditions, equipment for a trial is installed device for shunting of the affected phase both of foreign and Czech producers. Certain limitation of the method and possible risks when applying this method was not mentioned. It was caused by a simplified view of the whole issue and the lack of practical experience. Only in the first test applications and related measurements, whereby the positives of the method were not confirmed under all conditions, for example in [1] were mentioned possible reasons that caused the opposite, i.e. negative effect of the method, paradoxically leading to an increase of the fault current at the ground connection. The reasons that caused the negative effect of the method were theoretically described in 2009 and subsequently confirmed by practical measurement in the part of the distribution system of ČEZ Distribuce.

The principle of the method is clearly illustrated in Fig. 2, which shows that at shunting of the affected phase get to the division of the capacitive current and the compensating current to the earth connection point (index 1) and to the shunting point (index 2). It can therefore be expected that the fault current flowing through the fault point must be logically reduced. On the basis of this simple view, most experts make general conclusions about the efficiency of this method without being more thoroughly verified the anomaly mentioned in [1]. As will be shown below, the division of the fault current between the ground connection point and the shunt point takes in another way. This is due to the fact that the capacitive current of the medium voltage system is generated by all the terminals coming from the transformer station $110 \mathrm{kV} / \mathrm{MV}$, with the usual size of the area of the supply area being $500-1000 \mathrm{~km}^{2}$. It is important to realize the ways in which the capacitive and leakage currents flow in the current earth connection, i.e. in the state of capacitance, respectively voltage unbalance of the medium voltage system. The currents are generated by the phase-tophase voltage and pass through the network capacities and leads to the ground, and then return to the ground connection point and the affected phase back to the source. 
Their size is therefore limited by the size of the fault resistance and, to a small extent, the impedance of the conductor in the section between the power transformer and the ground connection point. In compensated networks, the capacitance is compensated by the inductive current of the coil normally connected between the power transformer star node and the ground. When a ground connection occurs, the star node has a phase voltage across the ground that generates an inductive current across the coil to the ground, which is then closed over the earth connection point and the same path as the capacitive and leakage currents. Compensation of these currents occurs only at the site of the earth connection. It is very important to realize this fact, as well as the fact that the coil current enters the ground from the transformer station grounding system, which is point source compared to the area of the power supply. While earth resistance can be neglected at the $50 \mathrm{~Hz}$ network frequency, it is necessary to consider in the calculations associated with the current distribution between the ground connection point and the shunt with the ground resistors, the resistance of the fault itself, the impedance of the affected phase conductor and the resistors in the shunt circuit. All of these resistors and impedances form real resistors that significantly affect the distribution of the current between the fault place and the shunt.

Figure 2 clearly shows the way of dividing currents and their designation, which is then used in further theoretical analysis and basic calculations.

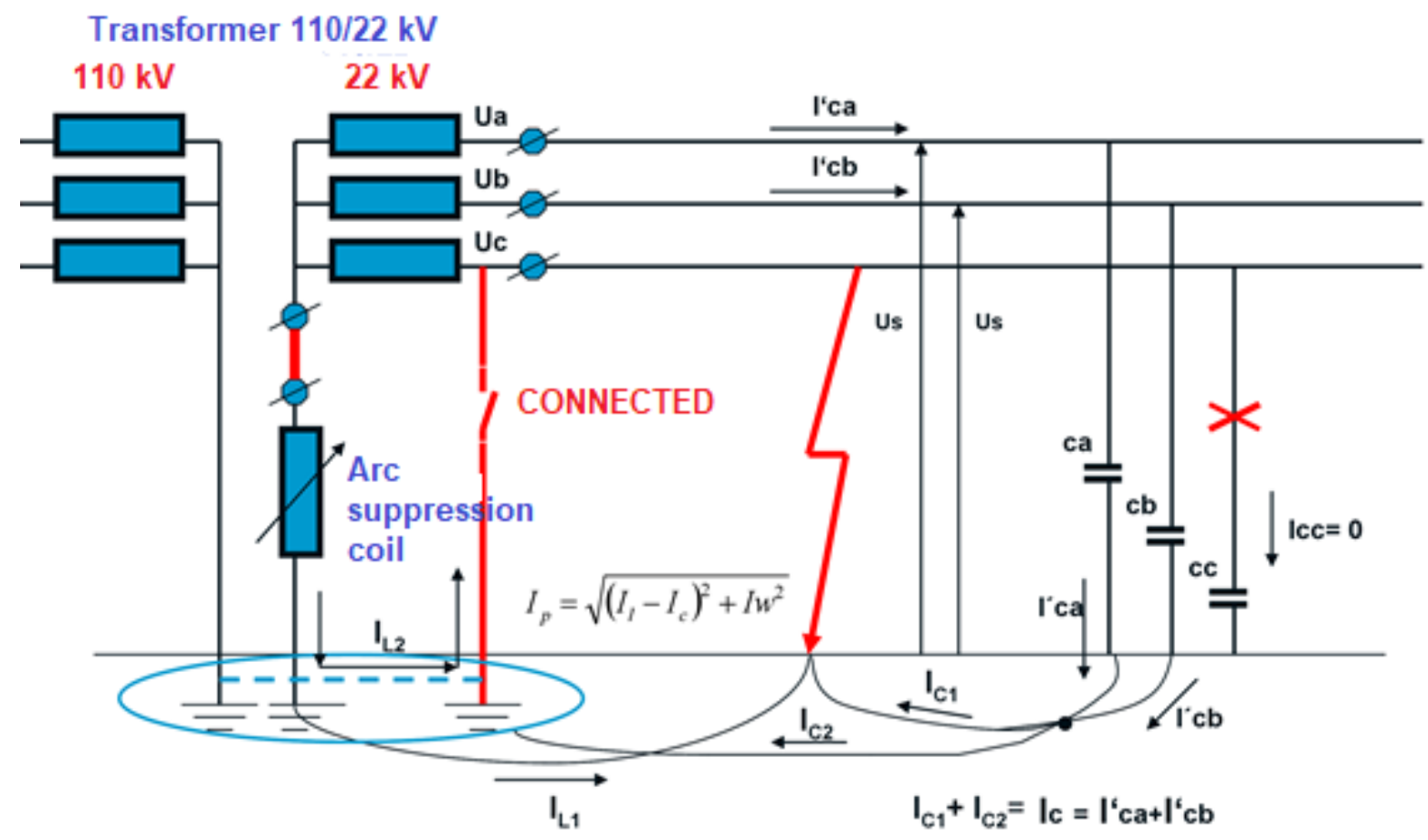

Fig. 2. The principle of shunting.

\section{B. Situation after a Ground Connection with a Connected Shunt}

When a parallel shunt is connected, a symmetrical or asymmetrical redistribution of the network capacitive current $I_{\mathrm{C}}$ between the fault site and the shunt, but an asymmetric distribution of the compensating current of the inductor $I_{\mathrm{L}}$ must always be obtained. This is due to the fact that the capacitive current of the MV system is a distributed parameter and springs from each "meter" of the length of the line, while the coil current flows from a "point source" that is a particular power transformer station $110 \mathrm{kV} / \mathrm{MV}$ a compensating coil and a common grounding system for this transformer station.

The division of the capacitive current $I_{C}$ between the ground connection place and the added shunt is given by Eq. (1):

$$
I_{\mathrm{C} 1}=I_{\mathrm{C}} \frac{R_{\mathrm{ztr}}+R_{\mathrm{sh}}}{\sqrt{\left(R_{\mathrm{ztr}}+R_{\mathrm{sh}}+R_{\mathrm{zdts}}+R_{\mathrm{p}}\right)^{2}+X_{\mathrm{v}}^{2}}},
$$

where

$I_{\mathrm{C} 1}$ the capacitive current in the location of the earth connection,

$R_{\mathrm{ztr}} \quad$ is the resistance of the $110 \mathrm{kV} / \mathrm{MV}$ transformer earth system,

$R_{\mathrm{sh}} \quad$ is the resistance of the shunt circuit,

$R_{\text {zdts }}$ resistance of the common ground of the distribution transformer station,

$R_{\mathrm{p}} \quad$ is the transition resistance of the fault,

$X_{\mathrm{v}} \quad$ the conductivity MV from the ZS point to the $110 \mathrm{kV} / \mathrm{MV}$ transformer,

$I^{\prime}$ ca here are increased capacitive phase currents in the earth connection. 
If there is a ground connection further to the transformer station, when checking the distribution of the flows of the capacitive currents by means of the earth connection and shunt it is necessary to calculate the reactivity of the line $X_{\mathrm{v}}$ between the ground connection and the $110 \mathrm{kV} / \mathrm{MV}$ power transformer.

By analogy, the size of the $I_{\mathrm{C} 2}$ current flowing through the shunt can be deduced, but it must be valid

$$
I_{\mathrm{C} 2}=I_{\mathrm{C}}-I_{\mathrm{C} 1} \text {. }
$$

So if there is a condition when it will pay that

$$
R_{\mathrm{ztr}}+R_{\mathrm{sh}}=\sqrt{\left(R_{\mathrm{zdts}}+R_{\mathrm{p}}\right)^{2}+X_{\mathrm{v}}{ }^{2}} .
$$

Then the distribution of the total capacitance current of the system $I_{\mathrm{C}}$ will be symmetric and will apply that

$$
I_{\mathrm{C} 1}=I_{\mathrm{C} 2} \text {. }
$$

The distribution of the compensation current of the choke $I_{\mathrm{L}}$ between the ground connection and the added shunt is given by Eq. 5

$$
I_{\mathrm{L} 1}=I_{\mathrm{L}} \frac{R_{\mathrm{sh}}}{\sqrt{\left(R_{\mathrm{ztr}}+R_{\mathrm{sh}}+R_{\mathrm{zdts}}+R_{\mathrm{p}}\right)^{2}+X_{\mathrm{v}}^{2}}}
$$

and in the same way as in Eq. (2), that

$$
I_{\mathrm{L} 2}=I_{\mathrm{L}}-I_{\mathrm{L} 1} \text {. }
$$

In the previous considerations, we assumed that before the beginning of the ground connection, the MV network was fully compensated and further we neglected the active component of the leakage current of the $I_{\mathrm{W}}$ network for the sake of simplicity. The distribution of this leakage current between the ground connection place and the shunt is the same as the distribution of the capacitive current of the network $I_{\mathrm{C}}$ according to Eqs. (1) and (2). For order to verify the theoretical analysis, the usual parameters of $110 \mathrm{kV} / \mathrm{MV}$ transformer station ground systems and common distribution transformer station earthling equipments were assigned to Eqs. (1) and (5). Capacitive current of $300 \mathrm{~A}$ was selected as a system parameter. This choice was not accidental since it was considered that the subsequent practical verification of the calculation would take place in the MV distribution system with comparable capacitive currents. Figure 3 demonstrates the dependence of the capacitive and inductive current at the fault site on the size of the resistance in the shunt circuit. Here are very illustrated the causes that ultimately lead to the increase of the fault current after the shunt connection. This phenomenon was named by the author of the theory [3] as "CI paradox" (Cimbolinec Ivan).

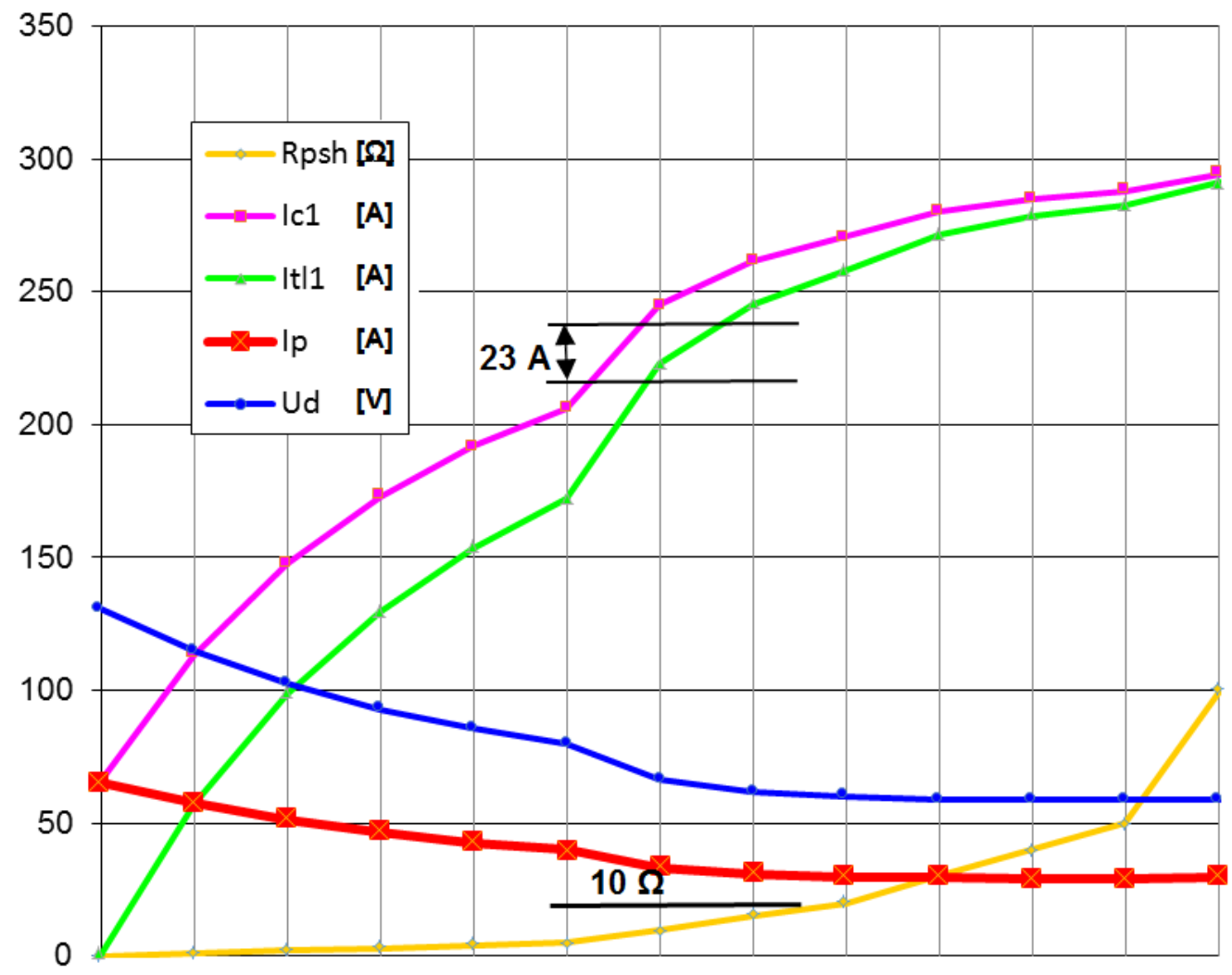

Fig. 3. Situation at fault location after shunt connection.

If successively, as it is shown in Fig, 3, to reduce the resistance in the shunt circuit, there will be an ever greater redistribution of the reactor current $I_{\mathrm{TL} 1}$ to the shunt circuit than the capacitive current $I_{\mathrm{C} 1}$. At the earth connection point, there was a decomposition of the capacitive and inductive component of the fault current and the increase of the total fault current. As can be seen from Fig. 3, now the fault current at the fault site will have a highly capacitive character and will be valid: 


$$
\left(I_{\mathrm{TL} 1}<I_{\mathrm{C} 1}\right) \neq 0
$$

and at the same time:

$$
\left(I_{\mathrm{TL} 1}<I_{\mathrm{Cl}}\right)>\left(I_{\mathrm{L}}-I_{\mathrm{C}}\right) .
$$

This negative property of the method can be partly influenced by the choice of suitable resistances in the shunt circuit and the state of the earth system of the transformer station $110 \mathrm{kV} / \mathrm{MV}$. Complete removal of this negative can be done by increasing the compensation current of the coil at the duration of the fault and simultaneously connected shunt, as described in [4].

\section{Practical Verification OF THE METHOD OF THE DS}

The measurement was made to ensure safe operation of the system only in a small part of the $22 \mathrm{kV}$ mixed system with a total capacitive currents $30 \mathrm{~A}$. This value was chosen to lie with a certain margin in the compensation zone of the compensating choke. It should be remembered that before the measurement itself, the choke was tuned by means of the automatic devise AL to resonance with the capacity of the measured area. After this tuning step, the automatic devise was turned off. The $22 \mathrm{kV}$ switchgear is a dual-bus system with an auxiliary bus, which allows the shunt to be connected to the substation main bus at any time. The fault current of the terminal could be conveniently measured using the Holmgren group of instrument current transformers of the respective terminal. The site of the earth connection was the mast distribution station Vodárna
Roudnice. The size of the contact voltage, which varies depending on the size of the fault current, was checked at this transformer station. This voltage fluctuated in dependence on the fault current. In the next course of the measurement, the metal earth connection was changed to resistance to confirm the positive influence of the method in faults with higher failure resistivity.

Despite certain limitations due to the small scale and technical state of the network, the measurements confirmed the theoretical conclusions and, in particular, the negative influence of the method on metallic earth connections.

\section{A. Transformer station 110/22 kV-Roudnice nad Labem - Experiments}

Figure 4 shows protocols $U_{0}, I_{0}$ for ground connection. The voltage $U_{0}$ (voltage on the choke for earth connections in the connected and disconnected shunt) and the current $I_{0}$ (earth fault current with the elimination of the shunt current) was measured continuously.

The fault current at the ground connection has an active character with the compensated system $22 \mathrm{kV}$ and its size corresponds to the range of the network.

Figure 5 illustrates the negative effect of the "Affected Phase Shunting" method in metallic earth connections and in low-resistance faults (CI paradox).

Figure 6 shows the positive effect of the method in the case of failures with a high transient resistance, in this case a resistance of $40 \Omega$.

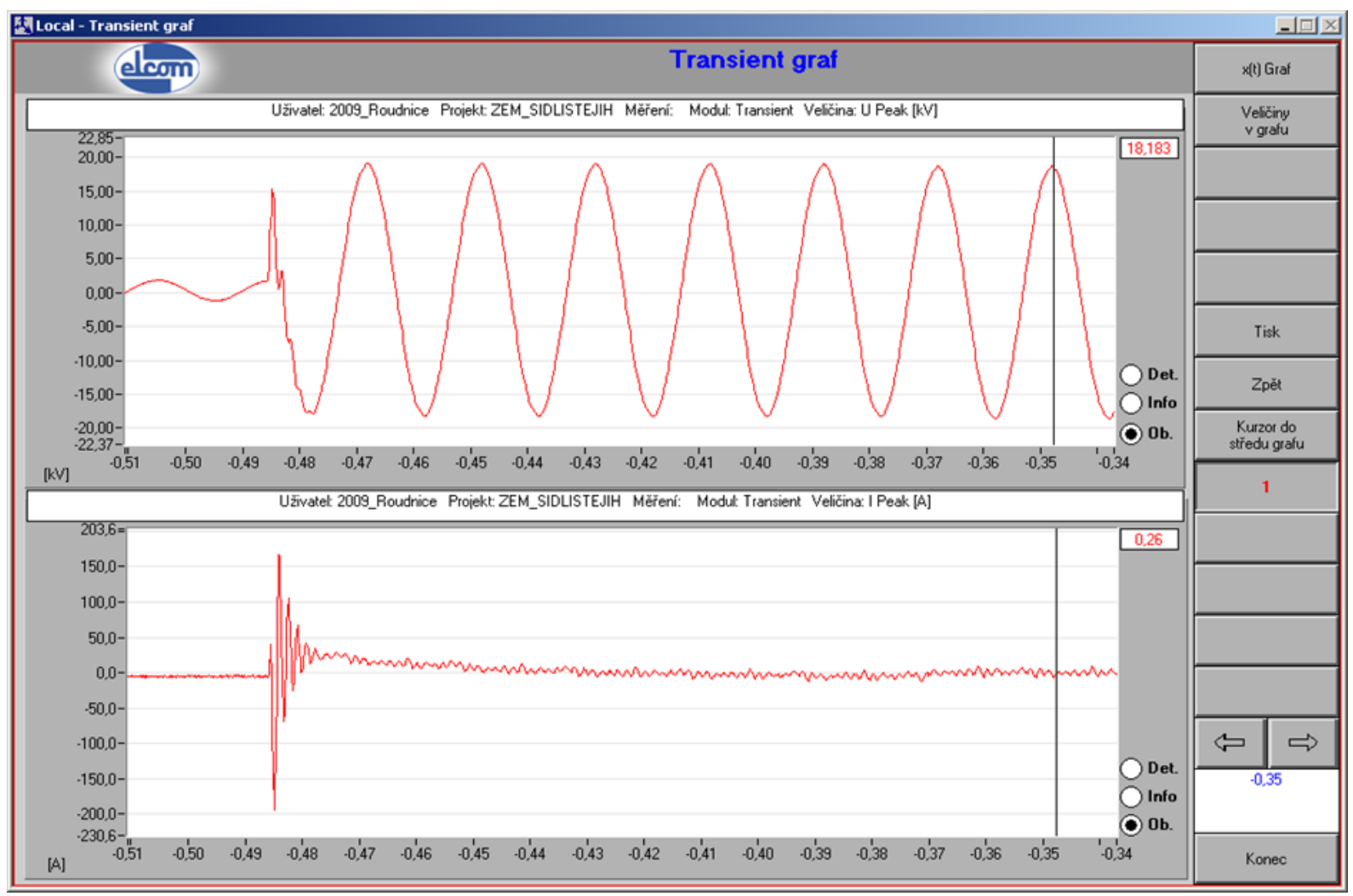

Fig. 4. Protocols $U_{0}, I_{0}$ for ground connection.

12:51 - Switching to earth fault without shunt connection - protocols $U_{0}, I_{0}$. 


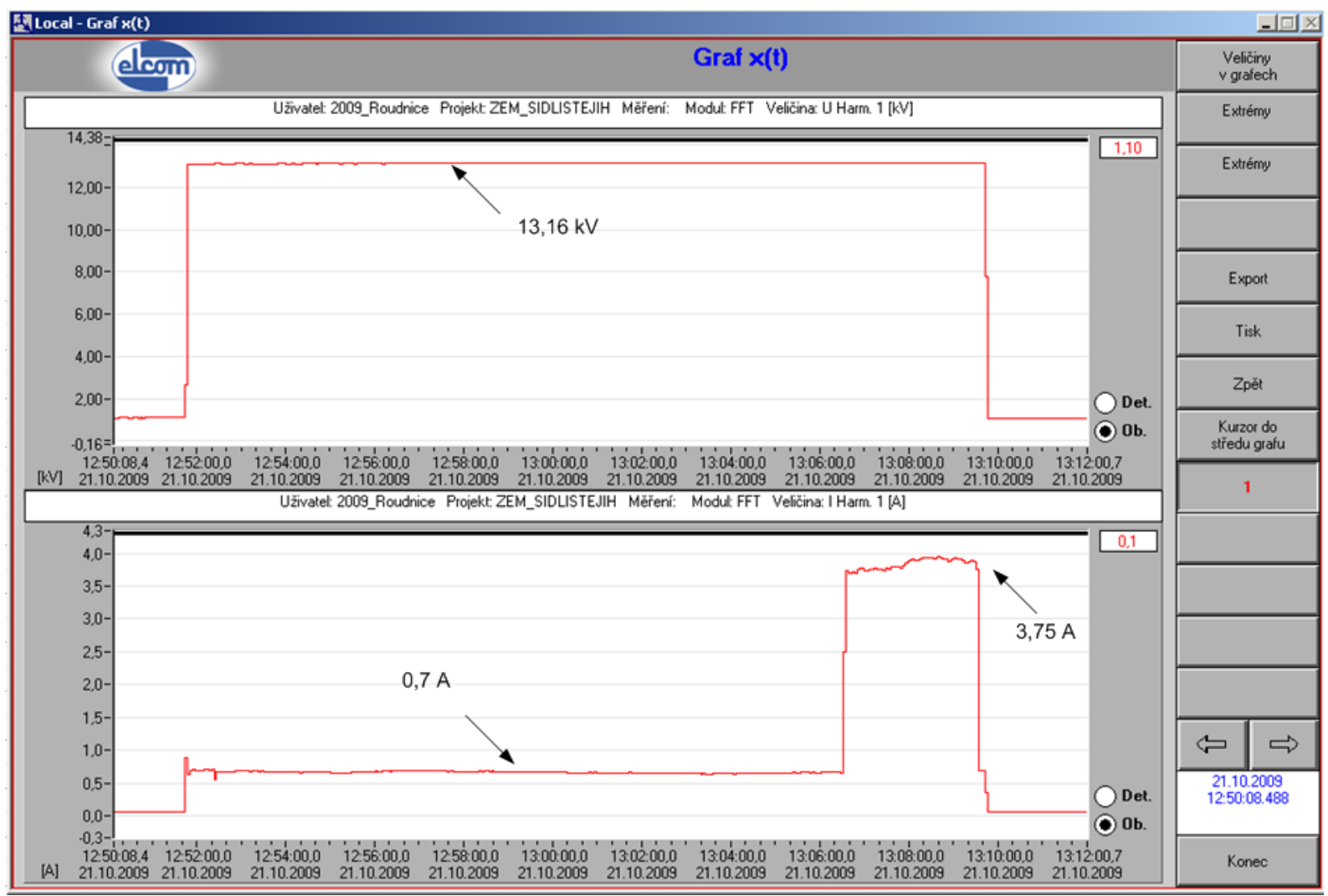

Fig. 5. Switched on shunt (metal earth connection).

12:51:40 - Switching on the earth fault. 13:06:30 - Switched on shunt (metal earth connection). 13:09:42 - Switching of the earth fault.

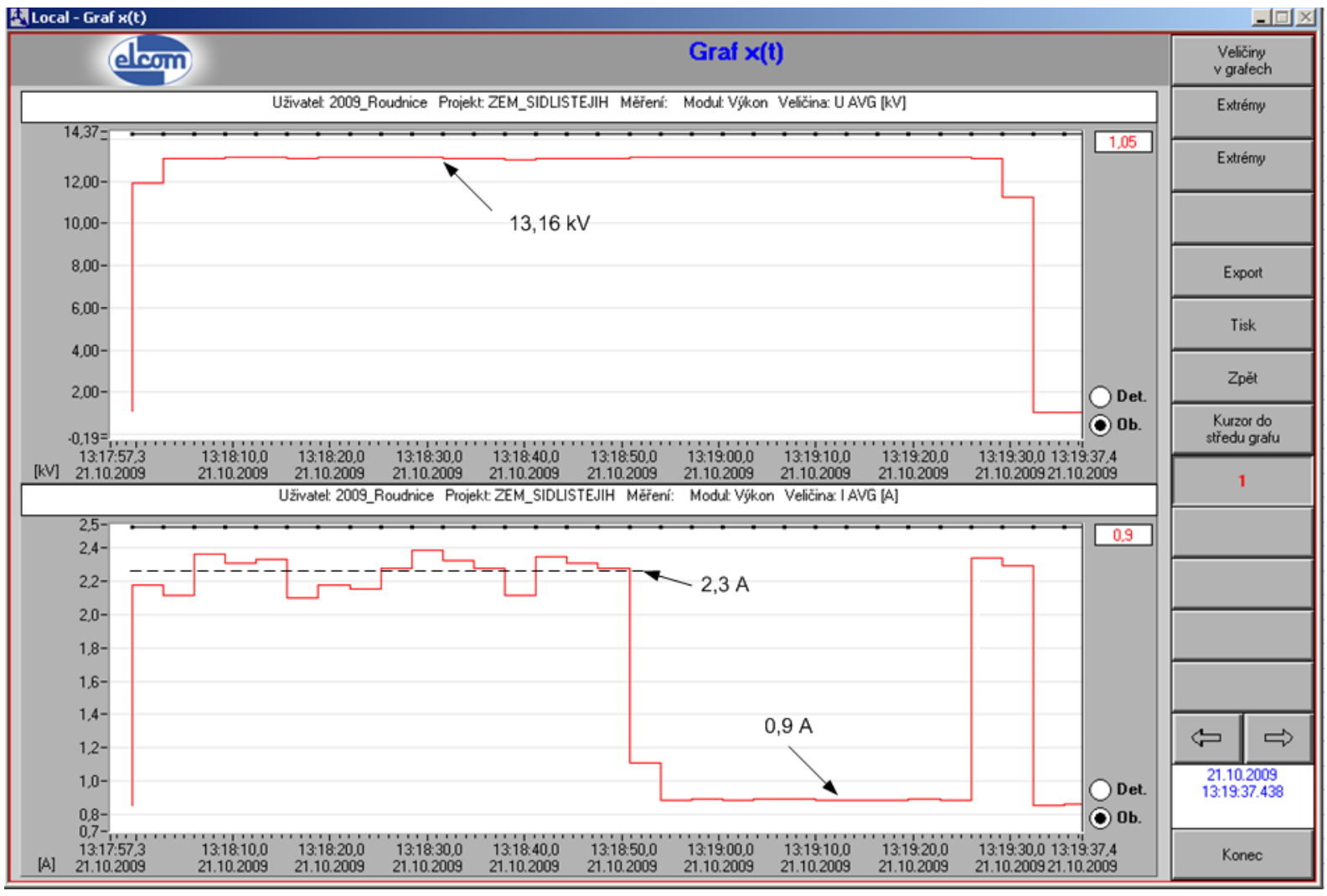

Fig. 6. Positive effect of the method with high transient resistance.

13:17:57 - Switching on the earth fault with a $40 \Omega$ failure resistance. $\quad$ 13:18:50 - Shunt ON. 13:19:30 - Switching off earth fault. 


\section{CONCLUSION}

Practical measurement in the $22 \mathrm{kV}$ distribution system of ČEZ Distribuce has shown a certain limitation of the described method. It can be agreed that in the case of failures with high failure transient resistance, this method has a very positive effect. These include, for example, earth-fallen conductors, where due to increased soil resistivity in the summer season with moisture deficiency, or in winter when frozen soil, there is a significant decrease in the fault current.

It should be borne in mind that earth fault types are not just grounded wires, but also frequent insulation faults in distribution transformers station, cable set faults and insulator failures on well-grounded masts of section disconnectors. In these cases, we must respect a certain limitation of the method, respectively deterioration of the condition after shunts. The deterioration of the condition occurs even without the influence of the load on the affected line by the operating current. It is important to realize that, especially for mast distribution transformer stations with smaller transformer capacity, where the operational current of the transformer on the MV side of the transformer is only a few amperes, the partial operating current cannot flow into the ground and then the fault resistivity back to the affected phase, can significantly affected size and character of the fault current caused by the phenomenon described (CI paradox).
At present that is in 2018 different types of shunt automation are installed in medium voltage networks and final measurements and evaluation are performed. We will be happy to present the overall results to readers.

\section{REFERENCES}

[1] Ladislav Pospíchal, Jaromír Dvořák, and Miloš Kaláb, "Poznámka k metodě přizemňování zemních spojení v sítích vysokého napětí," Elektroenergetika, No. 2, 2007.

[2] Petr Starý and Ivan Černý, "Ošetření místa zemního spojení a lokalizace poruchy v síti $22 \mathrm{kV}$ systémem přizemňování fáze," CIRED 2008.

[3] Ivan Cimbolinec, Tomáš Sýkora, Jan Švec, and Zdeněk Miller, "Použitelnost metody »Přizemnění postižené fáze« (shuntingu) při zemních spojeních v kompenzovaných sítích vn," CIRED 2009.

[4] Ivan Cimbolinec, Tomáš Sýkora, Jan Švec, and Zdeněk Miller, "Eliminace negativního vlivu metody Přrizemnění postižené fáze př́i zemním spojení v systémech vn," CIRED 2010.

[5] D. Topolánek, J. Orságová, P. Toman, and V. Dvořák, "Vliv přizemnění postižené fáze na bezpečnost sítí vn," CIRED 2010.

[6] D. Topolánek, J. Orságová, P. Toman, and V. Dvořák, "Zhodnocení funkce automatiky přizemnění postižené fáze během nízkoohmového zemního spojení vzhledem $\mathrm{k}$ nebezpečnému dotykovému napětí," CIRED 2011.

[7] Kompenzace kapacitnich zemních proudi̊ v sitich vysokého napětí, ČN 333070 (Czech Standard).

[8] D. Kouba, "Analýza účinnosti metody shuntování pomocí teorie dvojbranů.” CIRED 2012. 